\title{
Cause and Management of Patients With Failed Endonasal Dacryocystorhinostomy
}

\author{
Ji Sun Baek · Seong Hun Jeong · Jung Hye Lee · Hye Sun Choi · Sung Joo Kim · Jae Woo Jang \\ Department of Ophthalmology, Kim's Eye Hospital, Myung-Gok Eye Research Institute, Konyang University College of Medicine, Seoul, Korea
}

Objectives. Endonasal dacryocystorhinostomy (DCR) is a well-established treatment method in patients with nasolacrimal duct obstruction. However, there are a few reports about the overall management of failed endonasal DCR. We investigated the causes and management strategies of failed endonasal DCR.

Methods. This retrospective review included 61 patients (61 eyes) who had undergone revision surgery by the same surgeon after failed endonasal DCR between January 2008 and December 2012. The appropriate revision method was determined after analysis of the etiology of failure by the fluorescein dye disappearance test, nasal endoscopy, lacrimal irrigation, and probing. The criteria for success of the revision surgery were defined by the passage of fluid without resistance upon lacrimal irrigation and normalization of the tear meniscus height.

Results. The mean duration between the primary endonasal DCR and revision surgery was 15.3 months. The average follow-up period after revision surgery was 12.2 months. The most common cause of endoscopic revision surgery was membranous obstruction. Endoscopic revision surgery was performed in 48 patients, while lacrimal silicone tube intubation under endoscopy was performed in 13 patients. The most common indication for lacrimal silicone tube intubation was functional epiphora. The overall success rate of the revision surgery was $89 \%$.

Conclusion. The most common cause of failed endonasal DCR was membranous obstruction. When patients with failed endonasal DCR presented at the clinic, it is important to identify the cause of the failure. Revision surgery could increase the final success rate of endonasal DCR.

Keywords. Failed Endonasal Dacryocystorhinostomy; Revision Surgery; Functional Epiphora

\section{INTRODUCTION}

Endonasal dacryocystorhinostomy (DCR) is used to treat lacrimal drainage system obstructions using a nasal approach with an electrical burr [1]. The overall success rate of endonasal DCR is reported to range from $80 \%$ to $95 \%$ [2].

Endoscopic DCR has many advantages over external DCR; it ensures no external scar formation on the skin of the eyelid, direct visualization of the nasal anatomy, and preservation of the

\footnotetext{
- Received January 26, 2016

Revised April 25, 2016

Accepted May 24, 2016

- Corresponding author: Jae Woo Jang

Department of Ophthalmology, Kim's Eye Hospital, Myung-Gok Eye

Research Institute, Konyang University College of Medicine, 136 Youngshin-

ro, Yeongdeungpo-gu, Seoul 07301, Korea

Tel: +82-2-2639-7811, Fax: +82-2-2633-3976

E-mail: jjw@kimeye.com
}

medial canthal tendon for the lacrimal pump function. Endoscopic DCR is currently a well-established treatment method in patients with nasolacrimal duct obstruction. However, endoscopic DCR only has a short history of widespread use. Consequently, management protocols for failed endonasal DCR have yet to be established for surgeons performing endoscopic DCR. Some surgeons could try to solve the failed endonasal DCR in its degree. As such, there are only a few reports on the management of failed endonasal DCR, and these can be divided into two groups: endoscopic revisional surgery group [3,4], and functional epiphora group $[5,6]$. To date, there are a few reports about the overall management of failed endonasal DCR. Therefore, in the present study, we have evaluated the cause of failed endonasal DCR and investigated methods for the overall management of failed endonasal DCR. Our study would be helpful for surgeons planning the management of failed endonasal DCR.

Copyright (c) 2017 by Korean Society of Otorhinolaryngology-Head and Neck Surgery.

This is an open-access article distributed under the terms of the Creative Commons Attribution Non-Commercial License (http://creativecommons.org/licenses/by-nc/4.0)

which permits unrestricted non-commercial use, distribution, and reproduction in any medium, provided the original work is properly cited. 


\section{MATERIALS AND METHODS}

\section{Study design}

This study involved the retrospective evaluation of 61 eyes (61 patients) who had undergone revision surgery to treat the failed endonasal DCR by one surgeon (JWJ) at Kim's Eye Hospital between January 2008 and December 2012. The primary endonasal DCR had been performed by other several surgeons. In order to investigate the cause of failure, the surgeon performed lacrimal irrigation, probing using a Bowman probe, fluorescein dye disappearance test, and nasal endoscopy. Dacryocystography was not performed. Failed endonasal DCR was defined by the discovery of closed nasal ostium upon nasal endoscopy, no fluorescence in the nasal cavity with the fluorescein dye disappearance test, or complaint of functional epiphora after tube removal. Functional epiphora was defined by the presence of an appropriately sized and good-opened nasal ostium and the passage of fluid without resistance upon lacrimal irrigation, but with complaints of symptoms of epiphora and an increased tear meniscus height (TMH). The patients showed no signs of dry eye syndrome, such as punctate corneal erosion, filament, and foamy tear meniscus, or meibomian gland dysfunction, such as telangiectasia, erythema, notching, and hyperkeratinization in the eyelid. Revision surgery was broadly divided into two categories based on the cause of failure: endoscopic revision surgery and lacrimal silicone tube intubation. Because this study was a retrospective medial record review, no Institutional Review Board approval was necessary. The study adhered to the tenets of the Declaration of Helsinki.

\section{Surgical techniques}

Endoscopic revision surgery was performed in patients who did not show nasal ostium under nasal endoscopy. In cases with membranous obstruction of the nasal ostium, the membrane was removed using a diode laser. If the membranous obstruction of the nasal ostium was accompanied by canalicular obstruction, the canalicular obstruction was opened using a trephine, following which membranectomy was performed under nasal endoscopy using a diode laser. In patients with nasal ostium obstruction by granuloma or synechia formation, removal of the granu-

\section{H I G G H L I G G H T S}

- The most common cause of failed endonasal dacryocystorhinostomy (DCR) is membranous obstruction.

- Lacrimal silicone tube intubation is effective treatment method for functional epiphora.

- It is important to identify the cause of the failure to treat the failed endonasal DCR.

- Appropriate revision surgery might increase the final success rate of endonasal DCR. loma or synechiolysis was performed under nasal endoscopy. In all endoscopic revision surgeries, the lacrimal silicone tube was inserted after making the nasal ostium.

Lacrimal silicone tube intubation was performed in patients who showed nasal ostium under nasal endoscopy. Patients with functional epiphora were intubated with a lacrimal silicone tube through the good-opened nasal ostium under nasal endoscopy. If canalicular obstruction was revealed in patients with goodopened nasal ostium upon probing with the Bowman probe, the canalicular obstruction was opened by trephination using a trephine, following which the lacrimal silicone tube was inserted.

Postoperative care differed according to the revision procedure. After endoscopic revision surgery, each patient was prescribed oral antibiotics, antibiotic eye drops ( $0.1 \%$ levofloxacin), and steroid eye drops ( $0.1 \%$ fluorometholone). Patients were instructed to use $0.02 \%$ Mitomycin C (MMC) eye drops for 5 days, and instructed to use a steroid nasal spray and irrigate nasal cavity using normal saline. At every visit, endoscopic nasal examination and dressing were performed. The silicone tube was removed 3 months after surgery. For the patients with silicone tube intubation, each patient was prescribed oral antibiotics, antibiotic eye drops ( $0.1 \%$ levofloxacin), and steroid eye drops $(0.1 \%$ fluorometholone). The silicone tube was removed 6 months after intubation. All patients were followed up at least 1-month after tube removal.

Success of the revision surgery was defined by the passage of fluid without resistance upon lacrimal irrigation, absence of epiphora symptom, and normalization of the $\mathrm{TMH}$ at the last follow-up visit.

\section{RESULTS}

Of the total 61 patients, 46 were female $(75 \%)$ and the overall mean age was 54 years. Twenty eight patients were operated upon the right side and 33 on the left side. The mean interval between the primary and revision surgeries was 15.3 months. The average follow-up period after revision surgery was 12.2 months. The average follow-up period was $11.2 \pm 5.2$ months in endoscopic revision surgery group and $16.4 \pm 5.9$ months in lacrimal silicone tube intubation group. The overall mean preoperative and postoperative $\mathrm{TMH}$ values were $3.38 \pm 0.61 \mathrm{~mm}$ and $1.15 \pm 0.44 \mathrm{~mm}$, respectively. In the group of patients whose revision surgery was successful (i.e., the success group), the preoperative and postoperative TMH values were $3.44 \pm 0.57 \mathrm{~mm}$ and $1.00 \pm 0.23 \mathrm{~mm}$, respectively; the postsurgical TMH change in this group was significant $(P<0.001)$. In the group of patients whose revision surgery failed (i.e., the failure group), the preoperative and postoperative TMH values were $2.86 \pm 0.49 \mathrm{~mm}$ and $2.29 \pm 0.88 \mathrm{~mm}$, respectively; the postsurgical TMH change in this group was not significant $(P=0.103)$ (Table 1$)$.

Cause of failed endonasal DCR was divided into two groups- 
Table 1. Patient demographics and characteristics

\begin{tabular}{lc}
\hline Characteristic & Value \\
\hline Age (yr) & $54 \pm 10$ \\
Gender & $15(25)$ \\
$\quad$ Male & $46(75)$ \\
Female & \\
Side of surgery & $28(46)$ \\
Right & $33(54)$ \\
Left & \\
Preoperative tear meniscus height (mm) & $3.38 \pm 0.61$ \\
Among the entire study population & $3.44 \pm 0.57$ \\
In the success group & $2.86 \pm 0.49$ \\
In the failure group & \\
Postoperative tear meniscus height (mm) & $1.15 \pm 0.44$ \\
Among the entire study population & $1.00 \pm 0.23$ \\
In the success group & $2.29 \pm 0.88$ \\
In the failure group & $12.2 \pm 8.0$ \\
Follow-up period after surgery (mo) & $15.3 \pm 13.6$ \\
Duration between previous operation and & \\
revision surgery (mo) & \\
\hline
\end{tabular}

Values are presented as number (\%) or mean \pm standard deviation.

one is anatomical failure, while the other is functional failure. Anatomical failure was divided into two categories based on nasal endoscopic findings. The most common cause of anatomical failure was membranous obstruction in the nasal ostium (31 patients; $51 \%$ ); the other causes included membranous obstruction of the nasal ostium with canalicular obstruction (12 patients; $20 \%$ ), granuloma formation in the nasal ostium (4 patients; $7 \%$ ), and synechiae formation in the nasal ostium (1 patient; $2 \%$ ). These patients did not show the nasal opening under nasal endoscopy. Four patients $(7 \%)$ showed canalicular obstruction with good-opened nasal ostium under nasal endoscopy. And 9 patients (15\%) showed functional failure (Table 2).

The success rate of revision surgery was $89 \%$ (54 patients). The success rate of the endoscopic revision surgery was $90 \%$ (43/48 patients), while that of lacrimal silicone tube intubation was $85 \%$ (11/13 patients). The success rate according to the cause of failed endonasal DCR were as follows: membranous obstruction in the nasal ostium (27/31 patients; $87 \%$ ), membranous obstruction of the nasal ostium with canalicular obstruction (11/12 patients; $92 \%)$, granuloma formation in the nasal ostium (4/4 patients; $100 \%$ ), synechiae formation in the nasal ostium (1/1 patient; $100 \%$ ), functional epiphora (8/9 patients; $89 \%$ ), and canalicular obstruction with good-opened nasal ostium (3/4 patients; $75 \%$ ) (Table 3).

\section{DISCUSSION}

In this study, we achieved an overall success rate of $89 \%$ in revision surgery by one surgeon. Previously reported success rates of endoscopic revision surgery ranged from $60 \%$ to $94 \%$ [7-15].
Table 2. Causes of failed endonasal dacryocystorhinostomy

\begin{tabular}{lc}
\hline Cause & No. (\%) \\
\hline Anatomical failure & \\
$\quad$ Nasal opening obstruction & \\
$\quad$ Membranous obstruction & $31(51)$ \\
$\quad$ Membranous obstruction with canalicular obstruction & $12(20)$ \\
$\quad$ Granuloma formation & $4(7)$ \\
$\quad$ Synechiae formation & $1(2)$ \\
$\quad \begin{array}{l}\text { Intact nasal opening } \\
\quad \text { Canalicular obstruction with good-opened nasal ostium }\end{array}$ & $4(7)$ \\
Functional failure & \\
$\quad$ Functional epiphora & $9(15)$ \\
\hline
\end{tabular}

Table 3. Success rates of revision surgery after failed endonasal dacryocystorhinostomy

\begin{tabular}{lc}
\hline Cause & Success rate (\%) \\
\hline Endoscopic revision surgery & $43 / 48(90)$ \\
Membranous obstruction & $27 / 31(87)$ \\
Membranous obstruction with canalicular & $11 / 12(92)$ \\
obstruction & \\
Granuloma formation & $4 / 4(100)$ \\
Synechiae formation & $1 / 1(100)$ \\
Lacrimal silicone tube intubation & $11 / 13(85)$ \\
Functional epiphora & $8 / 9(89)$ \\
Canalicular obstruction & $3 / 4(75)$ \\
Total revision surgery & $54 / 61(89)$ \\
\hline
\end{tabular}

However, the criteria for success differed among the studies, and not all of the studies considered both anatomical and functional criteria for the success of surgery.

The cause of failed endonasal DCR is multifactorial, with the most common cause being granuloma in the nasal ostium due to excess scar tissue formation during the wound healing process. In addition, adhesion of the nasal ostium with the middle turbinate or the nasal septum, and common canalicular obstruction are known to cause failure of endonasal DCR [4]. In our study, membranous obstruction of the nasal ostium $(51 \%)$ were most common cause of failure of endonasal DCR, followed by membranous obstruction of the nasal ostium with canalicular obstruction (20\%), functional epiphora (15\%), granuloma formation in the nasal ostium (7\%), canalicular obstruction with good-opened nasal ostium (7\%), and synechiae formation in the nasal ostium $(2 \%)$.

The healing process is known to play an important role in the failure of endonasal DCR. Jordan et al. [16] reported that suppression of reepithelialization during the healing process can induce an inflammatory response as well as an excessive proliferation of capillaries that eventually form a pyogenic granuloma. This becomes a vicious cycle because of the inhibition of reepithelialization by the pyogenic granuloma. In the present study, we analyzed patients with granuloma formation around the nasal ostium (13 patients; $21 \%$ ) before reoperation; of the 13 pa- 
tients, 11 patients underwent reoperation because of membranous obstruction of the nasal ostium, and 1 patient each underwent reoperation because of granuloma formation in the nasal ostium and membranous obstruction of the nasal ostium with common canalicular obstruction. These results suggest that granuloma formation around the nasal ostium after primary endonasal DCR might be associated with the failure of primary endonasal DCR.

In our study, we analyzed the causes for reoperation of 43 patients according to the area of obstruction before the primary surgery; in patients with nasolacrimal duct obstruction, membranous obstruction of the nasal ostium accounted for $76 \%$ (19/25 patients), granulation formation in the nasal ostium for $12 \%$ (3/25 patients), and canalicular obstruction for $12 \%$ (3/25 patients) of the cases. In patients who presented with common canalicular obstruction in primary surgery, the causes for reoperation are as follows: membranous obstruction of the nasal ostium accounted for $80 \%$ (8/10 patients) and common canalicular obstruction for $20 \%$ (2/10 patients). In patients who showed canalicular obstruction before the primary surgery, the causes for reoperation included canalicular obstruction $(63 \% ; 5 / 8$ patients), membranous obstruction of the nasal ostium in $(25 \%$; $2 / 8$ patients), and common canalicular obstruction $(13 \% ; 1 / 8$ patients). The cause of failure of endonasal DCR seems to be associated with the area of obstruction before the primary surgery. However, we could not statistically analyze this correlation because of the small number of patients for whom the area of obstruction was known before the primary endonasal DCR. Further evaluation is required to determine the exact relationship between the cause of failure and the area of obstruction before primary endonasal DCR.

We prescribed the postoperative application of $0.02 \%$ MMC eye drops to all of the patients after the endoscopic revision surgery. MMC has been widely used in ophthalmic surgery for the prevention of granuloma formation. Several controlled studies have investigated the efficacy of MMC in the enhancement of the success of primary or revisional endonasal DCR [17-19]. The use of MMC could inhibit scarring and the formation of granulation tissue around the nasal ostium. In our hospital, the patients who underwent primary endonasal DCR were prescribed $0.02 \%$ MMC eye drops to inhibit granuloma formation around the ostium.

Endoscopic revision surgery aids the direct visualization of the site of any type of obstruction and helps ensure the appropriate size and position of the nasal ostium. Surgeons commonly perform endoscopic revision surgery to remove membranes and scar tissues by two methods. The first method is the same as the primary endoscopic DCR technique [5], and the second method involves the use of diode lasers, similar to the technique applied in the present study [20]. A few studies [21,22] have shown that DCR using diode laser is effective and has the shortest surgical time, with success rates similar to those of external or endonasal
DCR. Surgery using diode laser is a simple, rapid, and bloodless method for revision surgery to remove the cause of obstruction of the nasal ostium. A diode laser is a semiconductor that converts electrical energy into light energy that is mainly absorbed by the soft tissues. The use of diode lasers avoids damage caused by beam escape to the adjacent structures such as the canaliculus, which makes it safer compared to the other lasers; it also has the ability to cut tissue and perform coagulation and hemostasis [23].

The key to successful endoscopic revision surgery is creating an appropriate-sized and accurately positioned nasal ostium and a healthy lacrimal sac mucosa. An appropriate-sized and optimally located nasal ostium ensures complete exposure of the lacrimal sac and intraoperative visual assessment of the common canalicular patency. Healthy lacrimal sac mucosa can encourage the normal healing processes of the nasal ostium and help tear flow to the ostium. This was confirmed by manometric measurements in a lacrimal sac pressure study [24], which concluded that the lacrimal pump remains functional after DCR; however, the suction power might decrease in the fibrotic lacrimal sac, leading to epiphora.

In the patients with functional epiphora, we inserted a lacrimal silicone tube and achieved a success rate of $89 \%$ (8/9 patients) in the revision surgery. Although the exact cause of functional epiphora is unclear, several studies have investigated its potential causes. For instance, in one study [25], magnetic resonance imaging dacryocystography was used to evaluate the signal intensity at the site of the nasal ostium after instillation of artificial tears into the conjunctival sac before and after blinking; the results revealed that patients with functional epiphora showed reduced post-blinking signal intensities. This result implies a defect in the lacrimal pump function. Another study [26] reported increased fluorescein transit time from the conjunctival sac to the nasal ostium in patients with functional epiphora. Currently, there are no known methods to enhance the lacrimal pump function; however, lacrimal silicone tube intubation is known to encourage lacrimal pump function. The exact mechanism by which lacrimal silicone tube intubation relieves epiphora is unclear. Kim et al. [5] proposed the theory the following theory to explain the effect of the silicone tube on the lacrimal pump: first, the silicone tube controls the punctual position and enhances lacrimal pump function; second, the small canaliculi might act as capillary tubes, and the capillarity tends to be strong in patients who exhibit the narrow capillary phenomenon.

In our study, the mean follow-up period was 12.2 month; since the standard deviation was 8 months, the follow-up period varied greatly among the patients. This variation could be explained by two factors. First, the minimum follow-up period varies according to the revision surgery method. The follow-up period for endoscopic revision surgery is at least 4 months, while that for lacrimal silicone tube intubation is at least 7 months. In our study, average follow-up period was $11.2 \pm 5.2$ months in 
endoscopic revision surgery and $16.4 \pm 5.9$ months in lacrimal silicone tube intubation. It was not a short period if we checked follow-up period in each operation. The second factor was that, in the present study, patients who were satisfied with the surgery did not visit the hospital for follow-up despite having appointments for the same. Moreover, patients with symptoms of epiphora could easily visit the hospital without the need for an appointment because of good accessibility to the hospital.

All of the patients who underwent endoscopic revision surgery in the present study were inserted with silicone tubes. Many surgeons agree that the use of silicone tubing in primary DCR has both pros and cons. Among recently published studies, most have reported no advantage of the use of silicone tubing in primary DCR $[27,28]$, while some have reported negative effects of the use of silicone tubing on the surgical outcome of primary DCR [29]. However, there have been no reports on the role of silicone tubing in endoscopic revision surgery. We assumed that the possibility of obstruction of the nasal ostium by granuloma caused by lacrimal sac fibrosis was higher in endoscopic revision surgery compared to primary DCR, especially in patients who showed obstruction of the nasal ostium by granuloma after the primary DCR. Therefore, we believed that silicone tubing would help maintain the osteotomy site during the healing process. Moreover, even if granulation tissue was found to have formed during the follow-up period because of the silicone tubing, we could have removed the tissue easily in an outpatient clinic while still maintaining the osteotomy site. Further study about the effect of silicone tubing in endoscopic revision surgery is required.

The limitations of our study include its retrospective design and the fact that we did not evaluate other factors affecting lacrimal tear flow, such as lid laxity and conjunctivochalasis. In case patients with failed endonasal surgery present with these factors, and they are corrected, the success rate of revision surgery might increase further. Further studies investigating the factors that affect lacrimal tear flow are required.

In conclusion, membranous obstruction is the most common cause of failed endonasal DCR. The overall success rate of the revision surgeries in our study was $89 \%$. Additionally, our results indicate that lacrimal silicone tube intubation is an effective treatment procedure for patients with functional epiphora. In patients with failed endonasal DCR, it is important to identify the cause of surgical failure, because surgeons should decide the method for revision surgery on the basis of this cause. An appropriate revision surgery might increase the final success rate of endonasal DCR.

\section{CONFLICT OF INTEREST}

No potential conflict of interest relevant to this article was reported.

\section{ACKNOWLEDGMENTS}

This study is supported by Kim's Eye Hospital Research Center in an English revision

\section{REFERENCES}

1.Woog JJ, Kennedy RH, Custer PL, Kaltreider SA, Meyer DR, Camara JG. Endonasal dacryocystorhinostomy: a report by the American Academy of Ophthalmology. Ophthalmology. 2001 Dec;108(12): 2369-77.

2. Leong SC, Macewen CJ, White PS. A systematic review of outcomes after dacryocystorhinostomy in adults. Am J Rhinol Allergy. 2010 Jan-Feb;24(1):81-90.

3. Hull S, Lalchan SA, Olver JM. Success rates in powered endonasal revision surgery for failed dacryocystorhinostomy in a tertiary referral center. Ophthal Plast Reconstr Surg. 2013 Jul-Aug;29(4):267-71.

4. Lee TS, Shin HH, Hwang SJ, Baek SH. The results of revisional surgery for the failed endonasal DCR. J Korean Ophthalmol Soc. 2007 Feb;48(2):186-92.

5. Kim NJ, Kim JH, Hwang SW, Choung HK, LeeYJ, Khwarg SI. Lacrimal silicone intubation for anatomically successful but functionally failed external dacryocystorhinostomy. Korean J Ophthalmol. 2007 Jun;21(2):70-3.

6. Shams PN, Chen PG, Wormald PJ, Sloan B, Wilcsek G, McNab A, et al. Management of functional epiphora in patients with an anatomically patent dacryocystorhinostomy. JAMA Ophthalmol. 2014 Sep; 132(9):1127-32.

7. Mathew MR, McGuiness R, Webb LA, Murray SB, Esakowitz L. Patient satisfaction in our initial experience with endonasal endoscopic non-laser dacryocystorhinostomy. Orbit. 2004 Jun;23(2):77-85.

8. Metson R. Endoscopic surgery for lacrimal obstruction. Otolaryngol Head Neck Surg. 1991 Apr;104(4):473-9.

9. Ragab SM, Elsherif HS, Shehata EM, Younes A, Gamea AM. Mitomycin C-enhanced revision endoscopic dacryocystorhinostomy: a prospective randomized controlled trial. Otolaryngol Head Neck Surg. 2012 Nov;147(5):937-42.

10. Paik JS, Cho WK, Yang SW. Comparison of endoscopic revision for failed primary external versus endoscopic dacryocystorhinostomy. Clin Experiment Ophthalmol. 2013 Mar;41(2):116-21.

11. Weidenbecher M, Hosemann W, BuhrW. Endoscopic endonasal dacryocystorhinostomy: results in 56 patients. Ann Otol Rhinol Laryngol. 1994 May;103(5 Pt 1):363-7.

12. El-Guindy A, Dorgham A, Ghoraba M. Endoscopic revision surgery for recurrent epiphora occurring after external dacryocystorhinostomy.Ann Otol Rhinol Laryngol. 2000 Apr;109(4):425-30.

13. Zeldovich A, Ghabrial R. Revision endoscopic dacryocystorhinostomy with betamethasone injection under assisted local anaesthetic. Orbit. 2009;28(6):328-31.

14. Korkut AY, Teker AM, Ozsutcu M, Askiner O, Gedikli O. A comparison of endonasal with external dacryocystorhinostomy in revision cases. Eur Arch Otorhinolaryngol. 2011 Mar;268(3):377-81.

15. Choussy O, Retout A, Marie JP, Cozlean A, Dehesdin D. Endoscopic revision of external dacryocystorhinostomy failure. Rhinology. 2010 Mar;48(1):104-7.

16. Jordan DR, Brownstein S, Lee-Wing M, Ashenhurst M. Pyogenic granuloma following oculoplastic procedures: an imbalance in angiogenesis regulation? Can J Ophthalmol. 2001 Aug;36(5):260-8.

17. ApuhanT, Yıldırım YS, Eroglu F, Sipahier A. Effect of mitomycin C on endoscopic dacryocystorhinostomy. J Craniofac Surg. 2011 Nov;22 (6):2057-9. 
18. Ozkiris M, Ozkiris A, Goktas S. Effect of mitomycin C on revision endoscopic dacryocystorhinostomy. J Craniofac Surg. 2012 Nov;23 (6):e608-10.

19. Cheng SM, Feng YF, Xu L, Li Y, Huang JH. Efficacy of mitomycin C in endoscopic dacryocystorhinostomy: a systematic review and meta-analysis. PLoS One. 2013 May;8(5):e62737.

20. Ozsutcu M, Yenigun A, Meric A, Ozucer B, Dogan R, Gulkilik G, et al. Transcanalicular revision surgery for failed dacryocystorhinostomy. Clin Ter. 2013;164(6):e485-8.

21. Derya K, Demirel S, Doganay S, Orman G, Cumurcu T, Gunduz A Endoscopic transcanalicular diode laser dacryocystorhinostomy: is it an alternative method to conventional external dacryocystorhinostomy? Ophthal Plast Reconstr Surg. 2013 Jan-Feb;29(1):15-7.

22. Balikoglu-Yilmaz M,Yilmaz T, Taskin U,Taskapili M,Akcay M, Oktay MF, et al. Prospective comparison of 3 dacryocystorhinostomy surgeries: external versus endoscopic versus transcanalicular multidiode laser. Ophthal Plast Reconstr Surg. 2015 Jan-Feb;31(1):13-8.

23. Desiate A, Cantore S, Tullo D, Profeta G, Grassi FR, Ballini A. 980 $\mathrm{nm}$ diode lasers in oral and facial practice: current state of the science and art. Int J Med Sci. 2009 Nov;6(6):358-64.
24. Kamel R, El-Deen HG, El-Deen YS, El-Hamshary M, Assal A, Farid $\mathrm{M}$, et al. Manometric measurement of lacrimal sac pressure after endoscopic and external dacryocystorhinostomy. Acta Otolaryngol. 2003 Jan;123(2):325-9.

25. Detorakis ET, Drakonaki E, Papadaki E, Pallikaris IG, Tsilimbaris MK. Watery eye following patent external DCR: an MR dacryocystography study. Orbit. 2010 Oct;29(5):239-43.

26. Delaney YM, Khooshabeh R. Fluorescein transit test time and symptomatic outcomes after external dacryocystorhinostomy. Ophthal Plast Reconstr Surg. 2002 Jul;18(4):281-4.

27. Al-Qahtani AS. Primary endoscopic dacryocystorhinostomy with or without silicone tubing: a prospective randomized study. Am J Rhinol Allergy. 2012 Jul-Aug;26(4):332-4.

28. Feng YF, Cai JQ, Zhang JY, Han XH. A meta-analysis of primary dacryocystorhinostomy with and without silicone intubation. Can J Ophthalmol. 2011 Dec;46(6):521-7.

29. Smirnov G, Tuomilehto H, Terasvirta M, Nuutinen J, Seppa J. Silicone tubing is not necessary after primary endoscopic dacryocystorhinostomy: a prospective randomized study. Am J Rhinol. 2008 Mar-Apr;22(2):214-7. 